\title{
Erratum to: Mind Reading and the Art of Drafting Medical Opinions in Veterans Benefits Claims
}

\author{
James D. Ridgway
}

Published online: 29 June 2012

(C) Springer Science+Business Media, LLC. 2012

\section{Erratum to: Psychol. Inj. and Law (2011) 4:171-186 DOI 10.1007/s12207-011-9113-4}

The original version of this article unfortunately was published with errors introduced during the editing process, especially in the footnotes and references. The corrected version is given below.

\begin{abstract}
The Department of Veterans Affairs' disability compensation program is distinctly different from other benefits systems and legal claims of disability. A medical professional seeking to provide evidence to be used in deciding such a claim must understand how that evidence fits into the process so that he or she may present a complete and useful opinion. This article assists those providing expert opinions in veterans benefits claims by describing: (a) the kinds of adjudicators who will evaluate the opinions, (b) the legal requirements defining the types and amount of detail required, and (c) the basic substance of veterans law with which a medical examiner should be familiar so as to produce a complete and relevant opinion.
\end{abstract}

Keywords Veterans · Disability - Compensation · Benefits . Post-traumatic stress disorder.PTSD - Evidence - Expert opinion $\cdot$ Medical opinion $\cdot$ Adjudication process

Once upon a time, deciding veterans benefits claims was simple and logical, although not perfect. Prior to the institution of judicial review, when a veteran filed a disability claim, the

To obtain the corrected version, aside from using Springer services, interested parties could contact Mr. Ridgway directly through jridgway@law.gwu.edu.

The online version of the original article can be found at http:// dx.doi.org/10.1007/s12207-011-9113-4.

J. D. Ridgway $(\bowtie)$

The George Washington University School of Law,

Washington, DC, USA

e-mail: jridgway@law.gwu.edu relevant records would be gathered and given to a panel of medical and legal experts (Ridgway, 2010, pp. 268-270). The experts would each bring their own specialized knowledge to the discussion and issue a decision that applied medical science and applicable law to the facts of the case. The problem with this process was that the panels operated as black boxes, producing decisions that often denied claims with no explanation beyond a citation to "sound medical principles" (Cragin, 1994, p. 25). Such decisions may well have been correct as to the science and the law, but they were impossible to verify in the absence of any stated rationale. In practice, there were substantial doubts about whether the decisionmaking process was living up to its ideal, and Congress ultimately responded to political pressure by passing the Veterans Judicial Review Act (VJRA) (1988), which added judicial oversight to the Department of Veterans Affairs' (VA) claims process (Helfer, 1992; Light, 1992).

Once judicial review was instituted, it was necessary to disband these panels of experts in order to separate the evidence in a case from the application of the law to it. ${ }^{1}$ Unfortunately, this necessity was not foreseen by Congress when it drafted the VJRA. As a result, the re-engineering of the system caused by the disbandings occurred through ad hoc responses to decisions of the U.S. Court of Appeals for the Federal Circuit (Federal Circuit) and the U.S. Court of Appeals for Veterans Claims (CAVC), and has produced a disjointed system that unnecessarily fragments the evidencegathering system in a way that is both inefficient and prone to error, due to barriers and procedures that prevent physicians-including psychiatrists and psychologists ${ }^{2}$ - and adjudicators from communicating with each other (Ridgway,

\footnotetext{
${ }^{1}$ Ridgway (2010, pp. 272-273); discussing Colvin v. Derwinski (1991).

${ }^{2}$ Cases and other authorities in veterans law usually refer to "physicians" or "doctors" in discussing evidentiary issues. For consistency, this article is generally phrased in terms of the role of "psychologists." However, essentially everything discussed herein applies equally to other types of mental health professionals and to physicians generally.
} 
2010, pp. 268-270). The outcome is a system in which the most common errors are due to inadequate medical evidence (see Ridgway, 2009a, pp. 416-417). Unfortunately, there is no reform on the horizon that would replace the current system. Until reform is enacted, producing a high-quality medical opinion that is adequate for making a final decision on a veterans benefits claim will often require a bit of mind reading on the part of the examiner to anticipate all the information that an adjudicator might need. The purpose of this article is to assist those involved in VA's currently sub-optimal evidence gathering system in producing better results under the current regime.

Ultimately, the goal of medical evidence in VA's system is to communicate specific information to those who will decide the claim. This article will look at three different aspects of communicating through written medical opinions. Part I, "VA's Claims Adjudication Process," looks at who is the audience for a medical opinion in a veterans benefits case. Part II, "General Issues in Drafting Medical Opinions for Veterans Benefits Claims," discusses how a medical opinion can communicate effectively with this audience. Part III, "Issues Specific to the Elements of a VA Disability Compensation Claim," turns to what a medical opinion needs to communicate.

\section{VA's Claims Adjudication Process}

The golden rule of effective communication is that if the audience did not understand you, then you failed to communicate. Accordingly, the first step in understanding how best to communicate is to understand your audience and its needs. What might go without saying to one group must be explicitly detailed to another. Accordingly, to draft an adequate medical opinion in a veterans benefits claim, it is imperative to have some perspective on where that opinion fits into the larger process.

\section{The Role of Adjudicators in the Modern Claims Process}

The key to understanding the role of medical evidence in the current adjudication process is realizing that medical opinions in veterans' cases are essentially substitutes for live expert testimony in a trial-like setting. The CAVC has been fairly explicit on this point, and has used the Federal Rules of Evidence to describe the factors guiding the acceptability of medical opinions in veterans' cases:

Both VA medical examiners and private physicians offering medical opinions in veterans benefits cases are nothing more or less than expert witnesses. While the Federal Rules of Evidence are not binding in this Court, nor on the Board, the rules on expert witness testimony provide useful guidance that has been exhaustively vetted by both the Rules Advisory Committee and by the U.S. Congress. In U.S. district courts, expert testimony may be received from a suitably qualified expert under the following conditions: (1) The testimony is based upon sufficient facts or data; (2) the testimony is the product of reliable principles and methods; and (3) the expert witness has applied the principles and methods reliably to the facts of the case. ${ }^{3}$

In this analogy, VA adjudicators act much like judges conducting bench trials. They must first act as gatekeepers and then as finders of fact.

However, the claims adjudication system is distinctly different from the trial court setting that the CAVC was comparing in the above quote, because VA adjudicators must provide highly transparent decisions, and they have a substantial duty to gather adequate evidence before deciding a claim. ${ }^{4}$ In trials, juries and even judges usually operate as black boxes (Mashaw, 2001, p. 20). How well an expert communicated and what the decision maker concluded can only be inferred from the verdict. In contrast, in the VA system, adjudicators must give clear reasons for their decisions, including an explicit statement of how the medical evidence was evaluated. ${ }^{5}$ More importantly, the VA system is very different from a trial, in which the party with a vague, incomprehensible, or confusing medical expert simply runs a strong risk of losing. Because VA adjudicators have a duty to secure adequate evidence before deciding a claim, problems with medical evidence in the VA system will lead not to dismissal of the claims, but rather to delays, remands, and further development. Unfortunately, this can cause a claim to drag on for a decade or more before it is properly decided (Ridgway, 2010, pp. 268-269).

\section{The Levels of the Claims Processing System}

One of the crucial difficulties in drafting an adequate medical opinion for a benefits claim is that it must speak to a variety of audiences. In general, as discussed below a

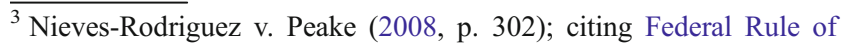
Evidence 702.

${ }^{4}$ See 38 U.S.C. § 5103A (2002); see also McLendon v. Nicholson, (2006, p. 83); noting that there is a "very low threshold" to trigger the duty to assist. Once the Secretary seeks a medical opinion, he generally cannot deny a claim until there is an adequate medical examination in the record. See Daves v. Nicholson (2007, p. 52); "Due process requires the Secretary to notify the claimant prior to the adjudication of the claim of his inability to obtain evidence he has undertaken to obtain, so that the claimant has a fair and reasonable opportunity to try and secure it or procure alternative evidence at a time when such information will be most useful to the adjudicator."; Sanders v. Principi (2003); highlighting the veteran-friendly nature of the VA adjudication process, and stating that, when a hearing examiner promised a medical examination but VA did not provide one, the Board must explain in its decision why it "would not or need not provide the promised examination."

${ }^{5}$ See Dennis v. Nicholson (2007, p. 22); "The Court has long held that merely listing evidence before stating a conclusion does not constitute an adequate statement of reasons and bases." (citing Abernathy v. Principi, 1992, p. 465).
} 
claimant is entitled to at least four "bites at the apple," and there are therefore numerous opportunities for a medical opinion to be found inadequate. ${ }^{6}$

First, a claim is decided by an adjudicator at one of fiftyseven Veterans Benefits Administration regional offices (ROs). ${ }^{7}$ These adjudicators are not attorneys. Although a plurality of RO adjudicators have college degrees, one quarter do not. ${ }^{8}$ Second, if a claim were denied, then a veteran would have the right to have it reexamined by a decision review officer (DRO) at the regional office (Riley, 2010, p. 89). The DRO is generally a senior adjudicator with more experience, but is still not an attorney (Riley, 2010, p. 89). Accordingly, the first audiences for a medical opinion consist of lay persons.

This is significant because, despite their training, these lay adjudicators do not think about claims in the same way as do attorneys (see Parker, 2009, pp. 217-219), and generally will not implement court decisions independently (see Riley, 2010, pp. 85-86). Instead, these adjudicators rely primarily on VA manuals and policy documents for guidance on how claims should be decided (see Parker, 2009, p. 218). Translating case law into specific rules of decision not only takes time, but also frequently loses many of the nuances of the decisions. Therefore, the regional office staff members are often ill-equipped to determine whether the evidence in any given case conforms to the requirements of the law.

\section{Veterans Benefits Adjudication System}

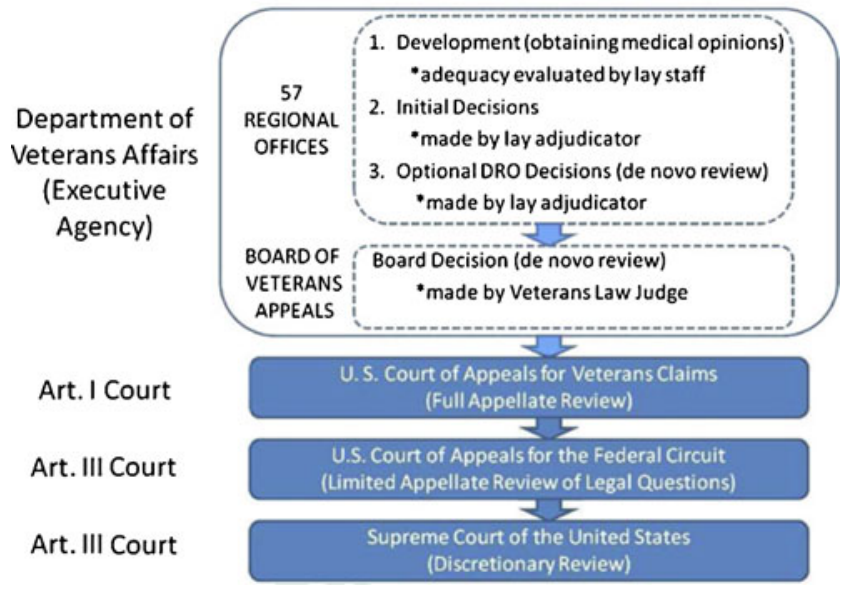

\footnotetext{
${ }^{6}$ This does not include appeals to the Federal Circuit or the Supreme Court. The Federal Circuit's limited jurisdiction does not permit it to review factual disputes or the application of the law to the facts, see 38 U.S.C. $§ 7292$ (d)(2) (2002), and certiori review by the Supreme Court is discretionary, extremely rare, and not granted for mundane factual appeals. ${ }^{7}$ These regional offices employ 15,000 adjudicators. See Department of Veterans Affairs (2010, p. I-20). Their operating budget in fiscal year 2011 totaled \$2.1 billion. See Department of Veterans Affairs (2011, p. I-2 C-1).

${ }^{8}$ See Harris $(2007$, p. 14). This survey was taken in concert with a report prepared by the Center for Naval Analysis (2007, pp. 193-94) for the Veterans' Disability Benefits Commission (2007, pp. 5-6, 13) with the full cooperation of VA. For a detailed description of VA's evidence gathering procedures, see Institute of Medicine of the National Academies (2007, pp. 139-57).
}

Third, in most instances, it is not until a claim is appealed to the Board of Veterans' Appeals (Board or BVA) in Washington, D.C., that the evidence is examined by an attorney. The BVA employs over 300 staff attorneys, who draft decisions for approximately sixty Board members (Terry, 2011, p. 3). As noted in the introduction, remands to the ROs by the BVA based upon inadequate medical opinions are frequent. However, the workload on the BVA is incredibly demanding, and there is often inadequate time to review the entire claims file and closely scrutinize all the evidence in the record. ${ }^{9}$ Fourth, as a result, in many cases, it is not until a claim is later appealed to the CAVC, years after the medical evidence in the case was drafted, that the veteran retains an attorney who has sufficient time to carefully dissect an opinion to determine if it could meet all of the detailed requirements discussed below (see Ridgway, 2010, pp. 285-286). Official statistics are not available, but there is little doubt that inadequate medical opinions are one of the leading bases of remands by the CAVC.

The overall picture is of a system in which the legal guidance and rulings provided are not easily transmitted from the courts to the front line and not carefully applied to the evidence in a case until years after it was gathered. Therefore, it is imperative that psychologists and practitioners know how to provide adequate medical evidence without being asked.

\section{The Process of Obtaining a Medical Opinion}

One reason that evidence problems are tragically frequent in the VA claims system is that there is little interaction between psychologists and adjudicators in the VA process. Although VA must obtain medical records from a veteran's private psychiatrist if made aware of them (38 U.S.C. $\S 5103 \mathrm{~A}(\mathrm{~b})$, 2002), VA generally has no duty to seek an opinion or further information from the veteran's doctor. ${ }^{10} \mathrm{Few}$ private psychologists understand how to provide an opinion that is adequate to grant a veterans benefits claim, and therefore are unlikely to provide sufficient evidence to do so.

\footnotetext{
${ }^{9}$ See Paralyzed Veterans of America et al. (2011), pp. 41-43; discussing the workload and staffing problems at the BVA; see also Board of Veterans' Appeals adjudication process and the Appeals Management Center, Hearing before the Subcommittee on Disability Assistance and Memorial Affairs (2007); testifying that, "over the course of the year the [BVA]'s fair share standards call for our attorneys to complete a total of 156 timely decisions of high quality, and for each of our line Judges to complete and sign 752 decisions."

${ }^{10}$ One exception was recently created by Savage v. Shinseki (2011), which required VA to seek clarification of a private medical examination that omits information if "the missing information is relevant, factual, and objective - that is, not a matter of opinion - and where the missing evidence bears greatly on the probative value of the private examination report." Id. at 270 . However, the phrasing of Savage is narrow on its face, and it remains to be seen what impact it will have. The Federal Circuit has rejected the argument that the Secretary has a duty to sua sponte provide a copy of the veteran's claims file to his treating physician. See Walch v. Shinseki, 2009, pp. 1377-78.
} 
Most medical evidence is obtained by requests for opinions from VA psychologists. ${ }^{11}$ Unfortunately, as has been detailed elsewhere, this process is deeply flawed. ${ }^{12}$ Communication between VA and a psychologist providing an opinion "is usually a one way street"; VA sends a request, and the examiner renders an opinion (Joyce, 2006). VA does not subpoena psychologists to testify ${ }^{13}$ or have them respond to interrogatories. ${ }^{14}$ Because there is no routine procedure for quickly and easily clarifying medical opinions, it is vital that any opinion provided be as clear and comprehensive as possible. Otherwise, it may take years of appeals and remands before the defects are identified and addressed.

\section{The Role of Medical Evidence}

Not only is it important to understand the general background of the adjudicators at the various levels in the system, it is necessary to know the role played by medical evidence in the process. This involves looking at both the division of responsibility between psychologists and adjudicators and at the other common forms of evidence that play different roles in the system.

\section{The Doctor vs. the Adjudicator}

Writing an effective medical opinion begins with understanding how it must be used by the adjudicator. In general, it is the role of the psychologist to provide information and opinions that are uniquely within his or her expertise, and it is the role of the adjudicator to take that information and apply it to the relevant legal criteria. ${ }^{15} \mathrm{~A}$ doctor is not required to opine on

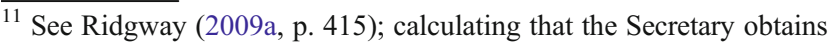
VA medical opinions in more than seventy-five percent of cases.

${ }^{12}$ See Ridgway (2009a). Although the good intentions and the professionalism of those who work for VA are not doubted, the current system simply does not allow for the communication and feedback necessary to convey the necessary information or improve the skills of those involved in evidence development. Ridgway (2009a)

${ }^{13}$ Indeed, the veterans claims system does not have a treating physician rule. See White v. Principi (2001, pp. 1380-1381).

${ }^{14}$ Although there is no statute or regulation providing for interrogatories in the VA system, the case of Gambill v. Shinseki (2009) contains a heated exchange between two Federal Circuit judges as to whether due process requires them. Compare Gambill v. Shinseki (2009, pp. 1313-1324) (Bryson, J. concurring) (arguing that they are not), with Gambill v. Shinseki (2009, pp. 1324-1330) (Moore, J., concurring) (arguing that they are).

${ }^{15}$ See Buczynski v. Shinseki (2011), pp. 225-226; “"A] medical opinion is adequate when the examiner provides sufficient detail so that the rating specialist can interpret the report and make a subjective determination as to whether the condition meets the rating criteria."; Stefl v. Nicholson (2007, p. 123); holding that physicians fulfill their role when they describe a claimant's symptoms "in sufficient detail so that the Board's "evaluation of the claimed disability will be fully informed one"' (quoting Ardison v. Brown, 1994, p. 407; internal quotes omitted); Moore v. Nicholson (2007, p. 218); holding that the Board fulfilled its role when it considered the medical evidence of record and translated it into a specific disability rating pursuant to the applicable diagnostic code; 38 C.F.R. § 4.2 (2011); "Different examiners, at different times, will not describe the same disability in the same language. . . . It is the responsibility of the rating specialist to interpret reports of examination ...."
}

matters outside the realm of medical expertise, and, in many cases, the legal criteria are based on non-medical factors. ${ }^{16}$ Psychologists should avoid commenting on legal issues, and instead should note when an issue is not medical. In particular, the question of whether a veteran's condition renders him or her unemployable is a legal question, not a medical one (Moore v. Nicholson, 2007, pp. 218-220). A psychologist can describe in detail the limitations caused by a veteran's symptoms, but the ultimate question of how those limitations translate into an employment disability is for the adjudicator to decide (Moore v. Nicholson, 2007, pp. 218-220).

\section{The Roles of Record Evidence and Lay Witnesses}

A related issue that often causes confusion is understanding how the other types of evidence in the claims file should be treated. As discussed in more detail below, ${ }^{17}$ it is important that an opinion clearly state what facts the psychologist is accepting as the premise of the opinion. Psychologists providing an opinion are ordinarily provided with the veteran's claims file. However, it is often not made clear how the doctor should treat the material in the file. There are two important principles to understand.

First, lay evidence is generally valid to prove facts that are within the realm of knowledge of a lay person. ${ }^{18}$ For example, veterans can describe symptoms of which they are capable of perceiving, and other witnesses can describe events, injuries, symptoms, or behaviors that are observable by a lay person. Therefore, it is important for a psychologist to address such statements in an opinion.

A trickier aspect of lay evidence is that lay persons are also considered competent to provide opinions on medical issues that fall within the common knowledge of a lay person. ${ }^{19}$ What constitutes medical common knowledge is not well defined. The Federal Circuit, which has limited jurisdiction to review the $\mathrm{CAVC},{ }^{20}$ has stated that a lay person is competent to identify a broken leg but not a form of cancer (Jandreau v. Nicholson, 2007, 1377 n.4). The Federal Circuit has also recognized that it is within the realm of common medical knowledge to consider a long gap between service and the beginning of symptoms as evidence against the claim (Maxson v. Gober, 2000, p. 1333).

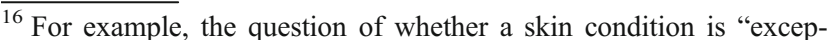
tionally repugnant" is not a medical issue (Buczynski v. Shinseki, 2011, p. 228).

${ }^{17}$ See infra section, "A Full and Accurate Factual Premise."

${ }^{18}$ See Charles v. Principi (2002, p. 374); holding that a veteran is competent to testify when his or her symptoms are capable of lay observation; Layno v. Brown (1994, p. 469) holding that lay testimony is competent to establish the presence of observable symptomatology. ${ }^{19}$ See Jandreau v. Nicholson (2007, p. 1377); holding that whether lay evidence is competent and sufficient in a particular case is a factual issue to be addressed by the Board.

${ }^{20}$ See supra section, "The Levels of the Claims Processing System."
} 
To illustrate this issue, a noteworthy case in the realm of psychological conditions is Davidson v. Shinseki (2009). The veteran in Davidson drowned in 1973, and this cause of death was listed as "accidental" on his death certificate (Davidson v. Shinseki, 2009, p. 1314). In 1999, the veteran's wife filed a claim for survivor benefits, asserting that the death was a suicide caused by a psychiatric disability related to service (Davidson v. Shinseki, 2009, p. 1314). "A VA psychologist reviewed the medical record and concluded that it was not likely that Mr. Davidson committed suicide, and that 'it is not at least as likely as not that, at the time of his death, the veteran was suffering from [an] acquired psychiatric disability that had its clinical onset in the service and caused or contributed materially in producing his demise"” (Davidson v. Shinseki, 2009, p. 1314; emphasis in original). The BVA denied the claim, and the CAVC affirmed that decision by the BVA. The Federal Circuit then held that the CAVC had erred in stating that "a valid medical opinion' was required to grant the claim," and remanded the matter back to the BVA so that the Board could give "due consideration" to the widow's lay testimony (Davidson v. Shinseki, 2009, p. 1316).

Neither the Federal Circuit nor the CAVC has elaborated on what "due consideration" of lay medical testimony may mean in circumstances similar to Davidson. However, the implication of Davidson was that the wife's testimony in support of the claim was potentially as probative as that of the VA psychiatrist's opinion against it. Accordingly, it would make sense for a medical opinion to address lay witnesses' beliefs about the origins of a veteran's condition, especially if those beliefs were mistaken and the opinion could identify reasons why the lay beliefs were invalid. For example, if a lay belief were based upon the proximity of a specific symptom to a specific event and medical research demonstrates that the coincidence were not probative, then it would be useful for an opinion to note that point.

\section{Corroboration and Credibility}

The second important principle is that there is generally no requirement that a veteran's assertions about what happened in the past be corroborated by records (see Buchanan v. Nicholson, 2006, p. 1337). Indeed, many veterans' service records have been lost or destroyed (see Stender \& Walker, 1974, p. 521). Although post-traumatic stress disorder (PTSD) claims have special rules ${ }^{21}$ in most cases the veteran's statements alone can be accepted as sufficient proof

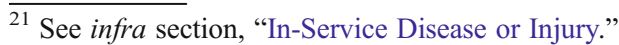

of past events. ${ }^{22}$ Therefore, it is inappropriate for a psychologist to reject the history provided by a veteran simply because it is not corroborated by records in his claims file. ${ }^{23}$

This is not to say that the history provided by the veteran must be accepted without question. However, the ultimate decision on the credibility of the veteran is one for the adjudicator, not the psychologist. ${ }^{24} \mathrm{~A}$ psychologist can still play an important role in this determination by indicating whether there were any medical reasons to accept or reject any information provided by the veteran. For example, it is perfectly appropriate for a psychologist to indicate that testing results or medical principles indicate that the veteran is likely exaggerating or inventing some or all of the symptoms reported (see, e.g., Forcier v. Nicholson, 2006, p. 419). It is also appropriate for an opinion to report that the symptoms or history reported by the veteran are inconsistent with the nature of his or her current diagnosis.

Another important way in which a medical examiner can comment upon the credibility of the history provided by a veteran is illustrated by Kahana v. Shinseki (2011). In Kahana, the veteran was seeking compensation for a right anterior cruciate ligament injury, but no such injury was noted in his service medical records (Kahana v. Shinseki, 2011, p. 430). The BVA ignored the veteran's testimony that he sprained his knee in service and rejected the claim, stating that, "[g]iven that a right ACL tear is quite a significant injury, one would expect to see at least some documentation of it in the [SMRs]. Also, one would expect that the [appellant] would have mentioned this right knee injury on his report of medical history at separation" (Kahana v. Shinseki, 2011, p. 434 (internal quotations omitted)). Nonetheless, the CAVC vacated the decision, and held that the BVA erred in "making a medical determination as to the relative severity, common symptomatology, and usual treatment of an ACL injury without citing to any independent

\footnotetext{
${ }^{22}$ If the events were related to combat, then the veteran's statements must be accepted as true under 38 U.S.C. $\S 1154$ (b) (2002), if they were "consistent with the circumstance, conditions, or hardships of such service," unless there were clear and convincing evidence contradicting the testimony (Collette v. Brown, 1996, p. 393). However, precisely what qualifies as "combat" is sometimes a difficult question, and it is ultimately the responsibility of the adjudicator, not the physician, to determine if the presumption under section 1154 applies. See Sizemore v. Principi (2004a); considering whether incoming fire is a necessary element of combat.

${ }^{23}$ However, this is not to say that the veteran's account of what happened in service is immune to challenge. See Holton v. Shinseki (2009); rejecting the argument that a physician must presume that the veteran's account of what happened in service is true.

${ }^{24}$ See Sizemore v. Principi (2004, p. 275); remanding for a new medical examination to "remove whatever taint there may be from this psychiatrist's overreaching in his report"; Owens v. Brown (1995, p. 433).
} 
medical evidence to corroborate its finding" (Kahana v. Shinseki, 2011, p. 434). The court concluded that the Board was not competent to know how the condition would manifest and what symptoms were likely to have been reported or recorded if such an injury were to have occurred. The essential lesson of Kahana is that determinations about what happened in the past based upon medical evidence and forensic reasoning should be done by an expert.

Ultimately, if there were conflicting information about the veteran's history or symptoms and there were no medical basis for resolving the conflict, then the psychologist should not comment upon the credibility of any of the evidence. Such commentary might undermine the opinion by suggesting that the psychologist was biased for or against the claim (see Sizemore v. Principi, 2004, p. 275). When there is conflicting evidence that will affect the opinion in some relevant way, a psychologist has two options. First, the psychologist can provide multiple, alternative opinions based upon the different possible views of the evidence. Alternative opinions can save months or years in adjudicating a claim by allowing adjudicators to decide the claim regardless of how the factual issues are resolved. Second, the psychologist can indicate that no opinion is possible until the factual issues are resolved. This approach is best used when there are a number of issues that need to be resolved and it would be difficult to address each potential version of the facts in the alternative. Regardless of the approach chosen, it is important to clearly identify all the issues that need to be resolved before an opinion is provided and whether there were any medical reason for resolving any of the issues in a particular way.

\section{Summary}

Writing a medical opinion that is useful to VA adjudicators can be a tricky proposition. The adjudicators need to issue detailed and transparent decisions, and, therefore, the opinions provided must be detailed as well. However, the context within which an opinion is sought is often unclear, and psychologists are frequently asked to review voluminous files containing conflicting evidence without guidance. Furthermore, the opinion must also speak to both the lay adjudicators on the front lines and the attorneys and judges who may review the claim later. Accordingly, an adequate medical opinion must be clear, precise, and comprehensive to allow adjudicators, judges, and attorneys to perform their functions. This is a difficult and sometimes frustrating task. However, it is easier when the psychologist has a grasp of how and what to communicate.

\section{General Issues in Drafting Medical Opinions for Veterans Benefits Claims}

Providing an adjudicator with everything needed to draft a complete and transparent decision in a veteran's claim can be daunting. In many ways, the opinion needs to stand in for the type of live testimony that would normally be provided at a trial or administrative hearing. Experts who testify frequently become familiar with the litany of questions that are normally asked, as well as the back-and-forth of clarifying particularly complex or difficult issues. This type of interactive testimony provides immediate feedback that helps the expert understand what needs to be communicated. Unfortunately, the VA process does not provide such feedback. Therefore, it can be difficult for a psychologist to know how to communicate effectively within that framework.

The CAVC has held that a medical opinion is adequate when it is based upon consideration of the veteran's prior medical history and examinations, and also describes the disability, if any, in sufficient detail so that the Board's "“evaluation of the claimed disability will be a fully informed one." ${ }^{25}$ This part of the article breaks this requirement into two main components. First, it looks at the foundation of an adequate medical opinion. In general, an adequate medical opinion must be based upon specific types of information in order to be useful to an adjudicator. Second, the section turns to the key aspects of communicating a conclusion effectively. All too often, an opinion will communicate a general sense of what the psychologist believes, but is not clear on some of the finer distinctions that are necessary to apply the law correctly. Understanding the elements of a clear foundation and conclusion allows a doctor to address key issues, regardless of whether the request clearly asked for particular, necessary information.

\section{The Bases of a Good Medical Opinion}

The first half of a good medical opinion is the foundation, namely what information the doctor considered in forming his or her conclusions. In general, medical opinions that (a) do not indicate whether the psychologists actually examined the veteran, (b) do not provide the extent of any examination, or (c) do not provide any supporting clinical data will be deemed inadequate (Claiborne v. Nicholson, 2005, p. 186). There are several components to a complete foundation.

\section{Credentials}

One traditional component of the foundation for expert courtroom testimony that is not generally emphasized in

\footnotetext{
${ }^{25}$ Ardison v. Brown (1994, p. 407); quoting Green v. Derwinski (1991, p. 124).
} 
the veterans claims system is the psychiatrist's credentials. The BVA "is entitled to assume the competence of a VA examiner" (Cox v. Nicholson, 2007, p. 569). As a result, the credentials of psychologists are nearly universally unstated, which creates a general sense in the claims adjudication system that doctors are largely fungible. The only issues that tend to arise occur when an opinion from a specialist is sought or recommended, but not obtained. ${ }^{26}$ Nonetheless, the CAVC has held that credentials are a factor that lay adjudicators can consider in weighing conflicting medical opinions, ${ }^{27}$ and there is no reason that physicians could not include a summary of their credentials in an opinion to help provide greater clarity in how the opinion should be weighed against conflicting medical or lay opinions.

\section{A Full and Accurate Factual Premise}

The first essential component of a valid medical opinion is a clear statement of the factual basis supporting the conclusion. An opinion based upon an inaccurate factual premise has little, if any, value. ${ }^{28}$ If the factual basis were unclear or incomplete, that would reduce the value of the opinion and would often render it inadequate even if the premises were not clearly incorrect. ${ }^{29}$ Even if there were no dispute as to the underlying facts, it is important for the medical opinion to discuss them so that it would be clear that none were ignored or overlooked.

One particularly common problem is that an opinion might mention only the history provided by the veteran during the psychiatrist's examination, or might state only that the veteran's claims file was reviewed. Such statements make the opinion unclear as to whether all relevant information was considered. As the CAVC has noted, "the claims file is not a magical or talismanic set of documents, but rather a tool to assist VA examiners to become familiar with the facts necessary to form an expert opinion to assist the adjudicator in making a decision on a claim" (Nieves-

\footnotetext{
${ }^{26}$ See, e.g., D'Aries v. Peake (2008, pp. 104-106); concluding that an opinion from a neurologist constituted "substantial compliance" with a request for an opinion from an internal medicine specialist.

${ }^{27}$ Cox v. Nicholson (2007, p. 569); "The level of training, education, and experience of the person conducting the examination is a factor that, if the Board affords more or less weight to the report because of that reason, must be thoroughly explained in its decision." Cox held that VA may presume that a nurse-practitioner has sufficient qualifications to render an opinion on a medical issue absent evidence to the contrary. Cox v. Nicholson (2007, p. 569).

${ }^{28}$ Reonal v. Brown (1993, p. 461); holding that the Board may reject a medical opinion that is based on facts provided by the veteran that have previously been found to be inaccurate; Swann v. Brown (1993, p. 233); same.

${ }^{29}$ See Kahana v. Shinseki (2011, 439 n.8); Lance, J., concurring; explaining the difference between an inaccurate factual premise and an incomplete one.
}

Rodriguez v. Peake, 2008, p. 303). It is how the opinion uses the information contained in the file that is important.

A related problem is that opinions frequently fail to address important lay statements in the claims file. Unfortunately, such statements are often difficult to find in the file because they can appear in a wide variety of ways. They commonly appear in hearing transcripts, formal statements in support of a claim, ${ }^{30}$ informal correspondence, and past medical opinions. The CAVC has recognized that it is unrealistic to expect doctors to exhaustively read "a compilation of documents that can run to thousands of pages (many of which . . . are often irrelevant to the issue before the psychologist)" (Nieves-Rodriguez v. Peake, 2008, p. 303). In practice, when VA requests a medical opinion, the requesting official usually puts tabs on relevant documents to bring them to the attention of the examiner (see Ridgway, 2009a, p. 421). However, the tabs are generally removed at some point, so it is impossible for a reviewing court to know what information was reviewed if it were not explicitly discussed in the opinion (Ridgway, 2009a, p. 421).

Given these facts, it is essential that a medical opinion describes the factual basis for the opinion in detail. This allows adjudicators to verify that the opinion is based on a complete and correct premise. Moreover, a very detailed discussion can strengthen the analysis and give more weight to the opinion.

\section{Prior Medical Records Opinions}

The second foundational element of a VA medical opinion is familiarity with the veteran's medical history. The CAVC has long held that an adequate medical opinion must "take[] into account the records of prior medical treatment, so that the evaluation of the claimed disability will be a fully informed one" (Green v. Derwinski, 1991, p. 124; see also Barr v. Nicholson, 2007, p. 311; Ardison v. Brown, 1994, p. 407). This rule recognizes that, even if a lay veteran were to fully and accurately report everything about his or her history that he or she were capable of observing, it would be quite likely that his or her medical records would have additional relevant information for a psychologist to consider.

A medical opinion is not required to address all of the prior medical opinions in the record or to comment on the analysis of prior opinions. Rather, it is the role of the adjudicator to weigh any such contrary opinions. ${ }^{31}$ However, directly

\footnotetext{
$\overline{{ }^{30} \text { Department }}$ of Veterans Affairs Form 21-4138. Retrieved from http://www.vba.va.gov/pubs/forms/vba-21-4138-are.pdf.

${ }^{31}$ See Moore v. Nicholson (2007, p. 218); "It is the responsibility of the rating specialist to interpret reports of examination in the light of the whole recorded history, reconciling the various reports into a consistent picture so that the current rating may accurately reflect the elements of disability present" (citing 38 C.F.R. $§ 4.2,2011$ ).
} 
addressing past medical opinions and critiquing them can give adjudicators a basis for favoring the opinion being provided over past opinions.

\section{Research}

A complete factual basis is critical, but it may not be sufficient. "[I]t must be clear on the record that the inability to opine on questions of diagnosis and etiology is not the first impression of an uninformed examiner, but rather an assessment arrived at after all due diligence in seeking relevant medical information that may have bearing on the requested opinion" (Jones v. Shinseki, 2010, p. 389). In cases involving common conditions, a psychiatrist's basic training and experience will often be a sufficient foundation for an opinion. However, if a condition were rare or if the veteran were to have submitted treatise evidence in support of a claim, then it might be necessary for an opinion to demonstrate that the psychologist had researched the issue and based the conclusion on current medical knowledge. In such cases, the opinion would benefit from addressing "whether [the psychologist] finds studies persuasive, whether there are other risk factors that might be the cause of the condition for which benefits are sought, and whether the condition has manifested itself in an unusual manner."32 Simply put, if it appears that a medical question is difficult or disputed, then the examiner must show that he or she has done the proper homework.

\section{Test Results}

A corollary to the duty to research relevant medical issues is the duty to gather information specific to the case. "When the [VA] Secretary's duty to provide a medical opinion is triggered, this duty includes the requirement that the Secretary provide reasonable tests and other examinations necessary to render a meaningful medical opinion" (Daves v. Nicholson, 2007, p. 51).

Where the medical examiner specifically states that a medical opinion cannot be provided without information not currently available, the Secretary's duty to assist requires that the Secretary determine whether that information may be reasonably obtained, and if so, make efforts to obtain it and seek an additional medical opinion which considers the relevant information (Daves v. Nicholson, 2007, p. 51).

\footnotetext{
32 Polovick v. Shinseki (2009, p. 53); citing Stefl v. Nicholson (2007, p. 124). Polovick held that statistical evidence constituted a proper basis for a medical opinion that a veteran's brain tumor was caused by exposure to Agent Orange, even though that condition was not presumptively related to exposure. Polovick v. Shinseki (2009, p. 54).
}

For example, in Daves v. Nicholson, the physician indicated that he could not provide an opinion as to the cause of the veteran's death without an autopsy. Based upon that statement, the CAVC held that the Secretary had to determine if an autopsy were available or could be obtained (Daves v. Nicholson, 2007, pp. 51-52). This duty is not limited to test results, however. For example, if it were to appear that there might be additional records available that would be useful in preparing a more definitive opinion, then the Secretary would have a duty to obtain those as well (see Green v. Derwinski, 1991, pp. 123-124).

\section{The Elements of a Good Medical Opinion}

Of course, once the foundation is established, then the opinion needs to state its conclusion. In general, the "probative value of medical[-]opinion evidence is based on the medical expert's personal examination of the patient, the physician's knowledge and skill in analyzing the data, and the medical conclusion that the physician reaches" (Guerrieri v. Brown, 1993, pp. 470-471). Producing a probative and persuasive opinion is easier when the psychologist is familiar with a number of factors.

\section{The Standard of Proof}

As with other legal claims, veterans claims are ultimately decided based upon the weight of the evidence. The veterans system uses a unique burden of proof known as "the benefit of the doubt." ${ }^{, 33}$ What this means in simple baseball terms is that "the tie goes to the runner." 34 If the evidence were in equipoise, then the claim would be granted. The most important application of this principle for psychologists to understand is that, "if the medical evidence in the record indicates that a disability has only two potential causes and at least one is related to service, then the inability of the medical examiner to provide a reason why one is more likely the cause of the claimant's disability would place the evidence in equipoise, and the benefit of the doubt rule would apply" (Jones v. Shinseki, 2010, p. 390).

Whether or not the psychologist believes that the case is close, it would be imperative to communicate the level of

\footnotetext{
${ }^{33}$ See Gilbert v. Derwinski (1990, pp. 53-56); tracing the origins of this standard back to the Civil War.

${ }^{34}$ Gilbert v. Derwinski (1990, p. 55). Lay persons are often misled by the word "doubt" into believing that the standard is related to the "beyond a reasonable doubt" standard in criminal law, which is much more demanding and places the burden on the government. See, e.g., Schram (2008, pp. 274, 287); asserting that VA does not apply the benefit-of-the-doubt standard and instead makes recommendations based upon the criminal law standard.
} 
certainty that he or she has in the opinion being provided. In close cases, an opinion can be inadequate if the adjudicator could not determine from the phrasing of the conclusion whether the psychologist believes the evidence is in equipoise or it weighs against the claim. This is why VA's requests for opinions usually ask the psychologist to phrase the conclusion as whether it were "at least as likely as not" that the condition were related to service. ${ }^{35}$

However, nothing prevents a psychologist from expressing an opinion with more certainty when appropriate. Psychologists should use more definite language when a case is not close. Not only does the greater degree of certainty add weight to the opinion, but it avoids giving the claimant a false impression that the outcome is debatable and that an appeal may have merit.

\section{Reasons for the Conclusion}

Of course, the most important part of an opinion's conclusion is its reasoning. "[A] medical examination report must contain not only clear conclusions with supporting data, but also a reasoned medical explanation connecting the two" (Nieves-Rodriguez v. Peake, 2008, p. 301). "Most of the probative value of a medical opinion comes from its reasoning. Neither a VA medical examination report nor a private medical opinion is entitled to any weight in a serviceconnection or rating context if it contains only data and conclusions" (Nieves-Rodriguez v. Peake, 2008, p. 304). "[A] conclusion that fails to provide sufficient detail for the Board to make a fully informed evaluation" is inadequate. ${ }^{36}$ An opinion "must support its conclusion with an analysis that the Board can consider and weigh against contrary opinions" (Stefl v. Nicholson, 2007, p. 124). As a result, "merely listing evidence before stating a conclusion" does not qualify as an adequate opinion (Dennis v. Nicholson, 2007, p. 22).

To be clear, no particular type of reasoning is required in every case. ${ }^{37}$ What matters is that the opinion clearly states its reasoning, and explains how the relevant facts, research,

\footnotetext{
${ }^{35}$ See, e.g., Haas v. Shinseki (2009, p. 389); “[T] he appellant's claim will be remanded in order for VA to provide such an examination, including an opinion as to whether it is at least as likely as not that the appellant's type-II diabetes mellitus was incurred in or aggravated by active service."; Stover v. Mansfield (2007, p. 487); "[T]he Board again sought a VHA opinion as to whether it was at least as likely as not that the veteran's disorder had worsened beyond its natural progression."

${ }^{36}$ Stefl v. Nicholson (2007, p. 124); see also Miller v. West (1998, p. 348 ); "A bare conclusion, even one reached by a health care professional, is not probative."

${ }^{37}$ See Mattern v. West (1999, p. 226); holding that deductive reasoning in a medical opinion is acceptable, even though inductive reasoning is more common.
}

observation, and other factors combined to produce the conclusion offered.

\section{Speculation}

A frequent problem in medical opinions is vague or speculative language. An opinion should avoid statements that the veteran's condition "may," "could," or "might possibly" be related to service. Such phrases are considered speculative and too ambiguous, making it impossible to determine the psychiatrist's belief as to the likelihood that the condition is related to service. ${ }^{38}$ As noted above, the issue that adjudicators face is not whether it were possible that a disability were related to service, but whether it were as least as likely as not.

However, the CAVC recognizes that, even with diligent research, a firm conclusion cannot be reached in every case. "An examiner's conclusion that a diagnosis or etiology opinion is not possible without resort to speculation is a medical conclusion just as much as a firm diagnosis or a conclusive opinion" (Jones v. Shinseki, 2010, p. 390). In such cases, the opinion should be as precise as possible as to what cannot be determined. "[I]t should be clear in the examiner's remarks whether it cannot be determined from current medical knowledge that a specific in-service injury or disease can possibly cause the claimed condition, or that the actual cause cannot be selected from multiple potential causes" (Jones v. Shinseki, 2010, p. 390). There is a vital difference between an opinion stating that a claim is theoretically possible and stating that there is no principled basis for choosing between two possible causes of the veteran's condition. ${ }^{39}$

\section{All Theories Reasonably Raised by the Record}

An opinion must address all medical issues related to theories of entitlement reasonably raised by the record. Technically, it is the adjudicators who must address every "theory of entitlement that was raised either by the appellant or by the evidence of record" (Robinson v. Peake, 2008).

\footnotetext{
$\overline{{ }^{38} \text { See Polovick }}$ v. Shinseki (2009, p. 54); holding that an opinion phrased as "may well be" was speculative and could not support an award of service connection; Bostain v. West (1998, pp. 127-128); stating that a medical opinion phrased in terms of "may" also implies "may or may not" and is speculative; Bloom v. West (1999, p. 187); concluding that an opinion phrased in terms of "could" was speculative without a clear theory of etiology.

${ }^{39}$ Jones v. Shinseki (2010, p. 390); Lance, J., concurring; "[I]f the medical evidence in the record indicates that a disability has only two potential causes and at least one is related to service, then the inability of the medical examiner to provide a reason why one is more likely the cause of the claimant's disability would place the evidence in equipoise, and the benefit of the doubt rule would apply."
} 
However, in practice, a medical opinion is needed to address most theories, because adjudicators lack the medical expertise required to decide them without expert evidence. ${ }^{40}$ To be clear, the BVA (and, therefore, the medical opinion) does not have "to assume the impossible task of inventing and rejecting every conceivable argument" (Robinson v. Peake, 2008, p. 553). However, if a psychologist were familiar with the core of the substantive law, then his or her medical expertise would often allow him or her to notice potential theories of entitlement suggested by the record. Addressing such theories without being asked - even if only to explain why the evidence did not actually support them - would not only speed the processing of the claim, but would reduce the administrative burden on VA to obtain additional opinions in the future.

\section{Issues Specific to the Elements of a VA Disability Compensation Claim}

After "who" and "how," the final element of a good medical opinion is "what" to communicate. Disability compensation benefits are the 600-pound gorilla that dominates the adjudication system. Although VA provides many other benefits, disability compensation claims - frequently referred to as "service connection" claims-represent the majority of applications and ninety-five percent of the claims that are disputed by claimants (see Ridgway, 2009b, pp. 115-116). At first blush, they are deceptively simple to describe. They are claims that the veteran has a current disability that was caused by a disease or injury that occurred in service. However, in practice, both the law and the underlying factual issues can be quite complicated.

\section{Eligibility}

The often over looked first element of a claim is establishing eligibility. Although this is not usually contested, there are still three relatively common medical issues that arise at this stage. Generally, a disability would be compensable if it could be traced to any injury or disease that occurred while a veteran were on active duty, whether it occurred in combat, during training, or off-duty. ${ }^{41}$ However, there are three key exceptions.

\section{Active and Inactive Duty for Training}

By definition, active service does not include active or inactive duty for training, except for specific circumstances.

\footnotetext{
$\overline{40}$ See introductory section.

${ }^{41}$ See Holton v. Shinseki (2009, p. 1366); “[A] service member's workday never ends."
}

Active duty for training qualifies as active service only if the veteran were "disabled or died from a disease or injury incurred or aggravated in the line of duty" (38 U.S.C. $\S$ 101(24)(B), 2002). Inactive duty for training would qualify only if the veteran were disabled or died from an injury or heart attack (but not a disease) that were incurred or aggravated in the line of duty (38 U.S.C. $\S 101(24)(C), 2002)$. Accordingly, if the claim were to involve one of these two periods, then the opinion must be precise as to what injury or disease caused the current condition and whether that event occurred in the line of duty.

\section{Willful Misconduct}

The second status issue is willful misconduct. Benefits are not generally available for disabilities that are "a result of the veteran's own willful misconduct or abuse of alcohol or drugs." 42 Suicide is defined as willful misconduct if it were "intentional," but the regulation also notes that "a person of unsound mind is incapable of forming an intent" (38 C.F.R. $\S 3.302(\mathrm{a}), 2011)$. Generally, "[ $\mathrm{t}]$ he act of suicide or a bona fide attempt is considered to be evidence of mental unsoundness" (38 C.F.R. $§ 3.302(b)(2), 2011)$. However, if an opinion were needed on the issue, then the psychologist should address whether the veteran was able to "realize the consequence of such an act, or was unable to resist such impulse" (38 C.F.R. § 3.302(b)(1), 2011).

Similarly, not all disabilities related to alcohol and drugs are excluded from benefits. As for alcohol:

The simple drinking of alcoholic beverage is not of itself willful misconduct. The deliberate drinking of a known poisonous substance or under conditions which would raise a presumption to that effect will be considered willful misconduct. If, in the drinking of a beverage to enjoy its intoxicating effects, intoxication results proximately and immediately in disability or death, the disability or death will be considered the result of the person's willful misconduct. Organic diseases and disabilities which are a secondary result of the chronic use of alcohol as a beverage, whether out of compulsion or otherwise, will not be considered of willful misconduct origin. (38 C.F.R. § 3.301(c)(2), 2011).

For drugs, "[ $[\mathrm{t}]$ he isolated and infrequent use of drugs by itself will not be considered willful misconduct; however, the progressive and frequent use of drugs to the point of addiction will be considered willful misconduct" (38 C.F.R. $\S 3.301(c)(3), 2011)$. Furthermore, even when substance abuse may not be granted service connection on a direct

\footnotetext{
$\overline{42} 38$ U.S.C. $\S \S 1110$ (basic entitlement for wartime service), 1131 (basic entitlement for peacetime service) (2002).
} 
basis, it may still be the basis of benefits if it were secondary to a service-connected condition, such as PTSD (Allen v. Principi, 2001). Therefore, if substance abuse were an issue in a case, then the examiner should be careful to precisely state the level of use and whether any usage were secondary to another condition.

\section{Insanity}

Insanity can be an issue if the claimant were discharged under conditions other than honorable. ${ }^{43}$ Such discharges may preclude eligibility for benefits unless the veteran was insane at the time that the offense at issue was committed. If the claimant or the evidence were to raise the issue of whether the claimant were insane at the time of an offense, then VA must make an independent determination on the issue (38 U.S.C. $\S 5303$ (b), 2002). Unfortunately, as the CAVC has noted, VA's definition of insanity is decades out-of-date and borders on incoherent. ${ }^{44}$ It defines an insane person as one:

who, while not mentally defective or constitutionally psychopathic, except when a psychosis has been engrafted upon such basic condition, exhibits, due to disease, a more or less prolonged deviation from his normal method of behavior; or who interferes with the peace of society; or who has so departed (become antisocial) from the accepted standards of the community to which by birth and education he belongs as to lack the adaptability to make further adjustment to the social customs of the community in which he resides. (38 C.F.R. § 3.354(a) (2011)).

A psychologist trying to apply this standard should focus on the language of the regulation and avoid trying to import concepts from more traditional definitions of insanity.

\section{Current Condition}

The next element of a service connection claim is a current condition, which generally means some diagnosed disability. ${ }^{45}$ One of the most important aspects of the benefits system that an examiner should understand is that the veteran's claim is not limited to any specific diagnosis.

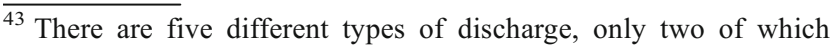
automatically entitle the recipient to "veteran" status under Title 38. See Eaton, Dantiki, and Gugliuzza (2010, p. 1157-1158).

${ }^{44}$ Gardner v. Shinseki (2009, p. 420 n.3); noting that the court first pointed out problems with the archaic standard in Zang v. Brown (1995).

${ }^{45}$ See Sanchez-Benitez v. West (1999, p. 285); “[P]ain alone, without a diagnosed or identifiable underlying malady or condition, does not in and of itself constitute a disability for which service connection may be granted."
}

Veterans are not generally competent to diagnose their own conditions and their claims, therefore, cannot be limited by their guesses as to the causes of their symptoms (see Clemons v. Shinseki, 2009, p. 5). Instead, a claim is generally for whatever the proper diagnosis of the symptoms might be, because "the fact that the appellant may be wrong about the nature of his condition does not relieve the Secretary of his duty to properly adjudicate the claim" (Clemons v. Shinseki, 2009, p. 6).

The case of Clemons v. Shinseki (2009) is a good illustration of the rule. In Clemons, the CAVC held that the Secretary erred in arguing that the veteran's claim for service connection for PTSD did not encompass service connection for any other psychiatric condition. The court concluded that, regardless of the label used by the veteran in his application, his "claim for benefits based on PTSD encompassed benefits based on an anxiety disorder and (or) a schizoid disorder because the evidence developed during the processing of the claim indicated that the symptoms for which Mr. Clemons was seeking VA benefits may have been caused by an anxiety and (or) schizoid disorder" (Clemons v. Shinseki, 2009, p. 3).

Therefore, if a psychologist were to disagree with the diagnostic label applied to the veteran, he or she should not simply state that the veteran does not have the claimed condition. Rather, the psychologist should address whether the veteran has any diagnosable condition based upon the symptoms at issue and, if so, whether that condition is related to service.

\section{In-Service Disease or Injury}

The next element of a claim is an in-service disease or injury meaning one that occurred while the veteran was on active duty in the military. "Injury" is interpreted very broadly for this purpose. Essentially, any event that occurred during one's time on active duty that can cause a medical condition can be considered an in-service injury. The most difficult issue related to this element involves PTSD claims. In a PTSD claim, the traumatic in-service event, the "stressor," is the in-service injury for purposed of the claim. Historically, the occurrence of the stressor had to be verified. If the stressor were related to combat, then verification of the veteran's participation in combat was sufficient (see Pentecost v. Principi, 2002, p. 128; Suozzi v. Brown, 1997, p. 311; 38 C.F.R. § 3.304(f)(2), 2011). However, for non-combat stressors, such as a personal assault, more specific corroboration is required (see 38 C.F.R. § 3.304(f)(4), 2011).

This stressor-verification requirement created a relatively common problem when a veteran reported multiple 
stressors, but only some of which could be corroborated (see, e.g., Cohen v. Brown, 1997). Accordingly, it is vital in many cases to identify the stressor to which a PTSD diagnosis is attributed. Frequently, an examination was inadequate because it is unclear whether the diagnosis was supported by stressors that could be verified. Therefore, a psychologist diagnosing a veteran with PTSD should explicitly attribute the diagnosis to a particular stressor when possible, or explicitly state that such an attribution is not possible. ${ }^{46}$

Recently, VA has amended its regulation governing stressor verification.

The amendment eliminates the requirement for corroborating that the claimed in-service stressor occurred if a stressor claimed by a veteran is related to the veteran's fear of hostile military or terrorist activity and a VA psychiatrist or psychologist, or a psychiatrist or psychologist with whom VA has contracted, confirms that the claimed stressor is adequate to support a diagnosis of PTSD and that the veteran's symptoms are related to the claimed stressor, provided that the claimed stressor is consistent with the places, types, and circumstances of the veteran's service. ${ }^{47}$

The precise contours of this new regulation have yet to be tested. ${ }^{48}$ However, it would seem that any diagnosis of PTSD should now address whether it were "related to the veteran's fear of hostile military or terrorist activity," if any ambiguity existed on that point.

\section{Nexus}

The most commonly disputed element of a compensation claim is the existence of a connection between the current condition and the in-service event. There are numerous ways that this element may be satisfied, and psychologists should have a basic understanding of each of the main theories so that they can provide opinions that allow adjudicators to properly address them all.

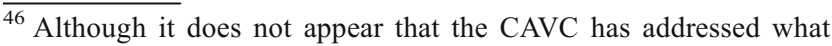
would happen if it were impossible to attribute a diagnosis when both verified and unverified stressors were at issue, the court has held that the benefit of the doubt applies when it is impossible to determine whether a symptom were attributable to a serviceconnected or non-connected condition. See Mittleider v. West (1998, p. 182).

${ }^{47}$ Stressor Determinations for Posttraumatic Stress Disorder (2010; amending 38 C.F.R. $\S 3.304(f), 2011$ ).

${ }^{48}$ Several veterans groups have filed a rulemaking challenge at the Federal Circuit arguing that the rule unfairly prevents private physicians from being used to corroborate claims. See National Organization of Veterans Advocates v. Department of Veterans Affairs (argued Aug. $5,2011)$. It remains to be seen whether the court will invalidate or modify the regulation.
}

\section{Direct Service Connection}

"Direct" service connection is service connection based upon competent medical evidence of a connection. Of course, this is the theory of service connection that psychologists are most frequently asked to address. As noted above, a medical opinion is not required to use any particular reasoning to reach the conclusion that a condition is related to service; what is important is that the bases and the reasoning behind the conclusion are well explained. ${ }^{49}$

\section{Presumptive Service Connection}

Certain conditions are presumed to be related to service, even without a medical opinion, under certain circumstances (see 38 U.S.C. § 1101(3), 2002). Logically, medical opinions are rarely needed to grant service connection on a presumptive basis. However, they are sometimes required when there is a dispute as to whether a particular condition falls within a presumptive category. Unfortunately, the relevant statutes and regulations are not updated frequently to keep pace with medical knowledge, and sometimes there are questions as to whether a diagnosis using current terminology falls within one of the presumptive categories. ${ }^{50}$ Accordingly, a medical professional should be aware of the presumptive conditions relevant to his or her specialty, so that he or she can note when a diagnosis falls within a presumptive category for which it may be ambiguous.

\section{Chronicity}

If a veteran had a "chronic" condition in service, then any future manifestation of that condition is presumed to be service connected (see 38 C.F.R. $\S 3.303(b), 2011$ ). The condition need not be even diagnosed in service, so long as the evidence is sufficient to determine in retrospect that the condition manifested in service (see Brannon v. Derwinski, 1991). There are many conditions that are defined as chronic by regulation (38 C.F.R. § 3.309(a), 2011). However, even though the Secretary has the power to add conditions to this list, he is under no obligation to keep this list current with medical advances (see Sacks v. West, 1998, pp. 317-318), and psychologists should understand that VA may not consider a condition chronic even though the condition may commonly be referred to as such in the medical community.

\footnotetext{
${ }^{49}$ See supra section, "Reasons for the Conclusion."

${ }^{50}$ See, e.g., Bonner v. Nicholson (2005); addressing a dispute as to whether the veteran's cancer was properly classified as one subject to a presumptive service connection.
} 
One particularly noteworthy category of presumptively chronic conditions is "psychoses" (38 U.S.C. § 1101(3), 2002). In 2009, the Federal Circuit held that this category includes schizophrenia (Groves v. Peake, 2008, pp. 13091310). Thus, if a psychologist were to determine that the veteran has a type of schizophrenia or any other psychosis and that condition manifested in service, then the opinion should state that conclusion.

\section{Continuity of Symptomatology}

A veteran may also be granted service connection for a condition if he or she has had the symptoms of that condition continuously since service (see 38 C.F.R. § 3.303(b), 2011). In such cases, it is not necessary to be able to determine the actual cause of the condition. Moreover, as the CAVC has often stressed, it is the continuity of symptoms - not the continuity of treatment - that is important. ${ }^{51}$ Ultimately, precisely what qualifies as continuous symptomatology is a factual issue. A medical opinion can be helpful in establishing whether continuity of symptomatology applies, by discussing precisely which of the veteran's symptoms are related to his or her current condition, and whether such symptoms are normally intermittent. A treating psychiatrist's opinion can be particularly useful when he or she can clarify the history of the current condition.

\section{Secondary Service Connection}

If a service-connected condition were to cause another disability, then that condition could also be granted service connection on a secondary basis (38 C.F.R. $\S 3.110(\mathrm{a}), 2011)$. Once again, this standard is liberally interpreted in favor of veterans, and the secondary condition need not be medically related to the primary condition. For example, in Roper v. Nicholson (Roper v. Nicholson, 2006), the CAVC indicated that secondary service connection could be granted for physical injuries that were the result of accidents that could have been avoided had the veteran not suffered from service-connected hearing loss (Roper v. Nicholson, 2006). So long as the cause-andeffect relationship is shown, secondary service connection may be awarded.

Medical professionals opining on the origins of a disability should be aware of all of a veteran's service-connected conditions and indicate whether any of them could be the cause of the disability at issue. This is particularly true for psychological conditions, such as depression, that may be the result of physical injuries.

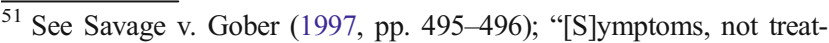
ment, are the essence of any evidence of continuity of symptomatology."
}

Disability Rating

Once a service connection claim has been granted, that claim is far from over, as a disability rating must then be assigned. Unlike a social security claim, in which the disability determination is binary, ROs must rate a serviceconnected condition as zero to one-hundred percent disabling, in ten-percent increments. The process of determining a proper disability rating can be quite complex, and reliance on medical opinions is usually critical.

\section{The Philosophy of Veterans' Disability Compensation System}

Before diving into the details, it is helpful to look at the basic philosophy behind the rating system. Disability ratings are generally objective, and the same symptoms result in the same rating for all veterans. For example, the loss of a hand would be rated the same, regardless of whether the veteran were trained as a physicist, a pianist, or a bricklayer. However, there is subjective rating available in many cases. A veteran whose condition renders him or her unemployable based upon his or her education, training, or experience, can be awarded a total disability rating based upon individual unemployability (see 38 C.F.R. § 4.16, 2011). In such a case, the veteran's background is relevant. However, the role of the psychologist in such cases is to explain what limitations are caused by the veteran's symptoms; the ultimate question of whether those limitations render the veteran unemployable is one for the adjudicator to make (see Moore v. Nicholson, 2007).

There have been many complaints that the current system is not fair. It was designed for World War II veterans and has only been updated on a sporadic and ad hoc basis. ${ }^{52}$ Some have complained that the system is not designed to consider quality of life issues. ${ }^{53}$ It has also been shown that the system tends to undercompensate those whose disabilities manifest earlier in life and those with mental disabilities (see Center for Naval Analysis, 2007, pp. 193-194). However, there do not appear to be any major reforms on the horizon. Accordingly, psychologists should be aware that VA adjudicators who need an opinion to assist in assigning a disability rating are primarily interested in an objective catalog of the veteran's symptoms.

\footnotetext{
$\overline{52}$ See Institute of Medicine of the National Academies (2007, p. x); noting that the current schedule was developed in 1945 and that some sections are still largely the same.

${ }^{53}$ See Veterans' Disability Benefits Commission (2007, pp. 5-6, 13; $c f$. Vasquez-Flores v. Shinseki, 2009, p. 1280); holding that the effects of a disability on a veteran's daily life "are not relevant to a disability rating made by a ratings specialist."
} 


\section{Rating Disabilities}

In the veterans benefits system, disabilities are rated using hundreds of "diagnostic codes" (38 C.F.R., ch. 4, 2011). Under each code exists one or more levels of disability, each with a list of symptoms that may be required to be awarded the specified disability rating. ${ }^{54}$ If the disability were to manifest with exceptional or unusual symptoms that were not listed in the diagnostic code, than an extraschedular rating might be awarded (see Thun v. Peake, 2008; 38 C.F.R. § 3.321(b), 2011). To the extent that there are symptoms that might or might not be attributable to the condition, then the opinion should also note that, because the benefit of the doubt will normally apply in the veteran's favor. ${ }^{55}$ Accordingly, it is important in a rating examination to list all of the symptoms caused by the disability at issue.

Despite the pages upon pages of codes for physical conditions, essentially all mental conditions are rated using a single "general rating formula" that focuses primarily on "social and occupational impairment levels." ${ }^{56}$ Although the regulations list numerous symptoms under each level of mental disability, those lists are not exclusive, and the CAVC has held that all symptoms should be considered in addressing the fundamental question of the veteran's level of social and occupational impairment (see Mauerhan v. Principi, 2002, pp. 443444). Moreover, the nature or quantity of the symptoms is not critical, nor is the veteran's Global Assessment of Functioning (GAF) score. ${ }^{57}$ Rather, the veteran's levels of social and occupational impairment are the essential issues, regardless of whether they were caused by few or many different symptoms. ${ }^{58}$

\footnotetext{
54 "Where there is a question as to which of two evaluations shall be applied, the higher evaluation will be assigned if the disability picture more nearly approximates the criteria required for that rating. Otherwise, the lower rating will be assigned." 38 C.F.R. § 4.7 (2011); see Cullen v. Shinseki (2010, p. 77).

${ }^{55}$ See Mittleider v. West (1998, p. 182). If a veteran were to have multiple service-connected psychiatric conditions, the examiner should try to attribute the symptoms to a specific condition if possible, but VA might use a single rating for all conditions to ensure that all symptoms were rated. See Amberman v. Shinseki (2009).

${ }^{56}$ See Mauerhan v. Principi (2002); discussing 38 C.F.R. § 4.130, (2011); see also Sellers v. Principi (2004, p. 1327); affirming the CAVC's holding in Mauerhan that symptoms listed in the DSM-IV supplement, rather than replace, the criteria listed in 38 C.F.R. $§ 4.130$ (2011).

${ }^{57}$ See Brambley v. Principi (2003, p. 26); holding that a GAF score is only one factor in determining an appellant's disability.

${ }^{58}$ Mauerhan v. Principi (2002, p. 443); "If the evidence demonstrates that a claimant suffers symptoms or effects that cause occupational or social impairment equivalent to what would be caused by the symptoms listed in the diagnostic code, the appropriate, equivalent rating will be assigned."
}

\section{Effective Date}

The final element in a disability claim is the effective date. Although determining a proper effective date can be a complex and confusing problem (see Ridgway, 2010, pp. 283-286), psychologists need not try to understand all the technical aspects. What is important is that, in general, the effective date of an award of benefits will be based upon either the date the claim was filed or the date that disability or increase in severity manifested. Veterans often fail to communicate clearly to adjudicators precisely when their symptoms began. Therefore, recording this information in an examination report will often assist in determining the proper effective date if benefits were to be awarded.

As a side note, medical records are not generally considered claims for benefits. ${ }^{59}$ Therefore, to protect a veteran's effective date, if a veteran were to mention during an examination that he or she wanted to seek benefits for a condition, then the psychologist should advise the veteran to file an application immediately with the nearest VA regional office.

\section{Conclusion}

Providing a complete and useful medical opinion in a veterans benefits claim has become quite difficult. Although many other aspects of the system remain informal, the requirements of an adequate medical opinion have become detailed and demanding. In essence, a medical opinion must now substitute for live testimony on a series of complex medical issues. For this testimony to be useful, a proper foundation must be laid, and the conclusions must be thoroughly explained. The difficulty of this task is further compounded because there is no questioner present during the drafting of an examination to provide feedback or seek clarification.

It can be deeply frustrating, especially for medical professionals, to perform the work as requested and then be told that it was inadequate. Unfortunately, this happens every day in the veterans benefits system because private and VA psychologists are not asked for all the information that is necessary to produce proper medical opinions. Until a better system is devised, veterans will be far better served if the psychologists involved in their claims become more familiar with the basic aspects of the adjudication system so that they can be more proactive in drafting opinions.

One hopes that at some point in the future, VA adjudicators will be able to communicate in some manner directly with medical experts as they did in the past, although under

\footnotetext{
${ }^{59}$ Under certain circumstances, medical records can be considered a claim for an increased rating or a claim to reopen a previously denied claim. See 38 C.F.R. $§ 3.157$ (2011).
} 
a revised, transparent system in which veterans can safely place their trust. In the meantime, psychologists must rely on a little mind reading and much legwork to answer all the important questions that need to be answered in order to effectively process these claims.

\section{References}

Abernathy v. Principi, 3 Vet. App. 461 (1992).

Allen v. Principi, 237 F.3d 1368 (Fed. Cir. 2001).

Amberman v. Shinseki, 570 F.3d 1377 (Fed. Cir. 2009).

Ardison v. Brown, 6 Vet. App. 405 (1994).

Barr v. Nicholson, 21 Vet. App. 303 (2007).

Bloom v. West, 12 Vet. App. 185 (1999).

Board of Veterans' Appeals adjudication process and the Appeals Management Center, Hearing before the Subcommittee on Disability Assistance and Memorial Affairs, of the House Committee on Veterans' Affairs, 110th Cong. (2007) (statement of James P. Terry, Chairman, Board of Veterans' Appeals). Retrieved from http://archives.veterans.house.gov/hearings/hearing.aspx? NewsID $=2042$.

Bonner v. Nicholson, 19 Vet. App. 188 (2005).

Bostain v. West, 11 Vet. App. 124 (1998).

Brambley v. Principi, 17 Vet. App. 20 (2003).

Brannon v. Derwinski, 1 Vet. App. 314 (1991).

Buchanan v. Nicholson, 451 F.3d 1331 (Fed. Cir. 2006).

Buczynski v. Shinseki, 24 Vet. App. 221 (2011).

Center for Naval Analysis (2007). Final report for the Veterans' Disability Benefits Commission: Compensation, survey results, and selected topics.

Charles v. Principi, 16 Vet. App. 370 (2002).

Claiborne v. Nicholson, 19 Vet. App. 181 (2005).

Clemons v. Shinseki, 23 Vet. App. 1 (2009).

Cohen v. Brown, 10 Vet. App. 128 (1997).

Collette v. Brown, 82 F.3d 389 (Fed. Cir. 1996).

Colvin v. Derwinski, 1 Vet. App. 171 (1991).

Cox v. Nicholson, 20 Vet. App. 563 (2007).

Cragin, C. L. (1994). The impact of judicial review on the Department of Veterans Affairs' claims adjudication process: The changing role of the Board of Veterans' Appeals. Maine Law Review, 46, 23-41.

Cullen v. Shinseki, 24 Vet. App. 74 (2010).

D'Aries v. Peake, 22 Vet. App. 97 (2008).

Daves v. Nicholson, 21 Vet. App. 46 (2007).

Davidson v. Shinseki, 581 F.3d 1313 (Fed. Cir. 2009).

Dennis v. Nicholson, 21 Vet. App. 18 (2007).

Department of Veterans Affairs (2010). Fiscal year 2010 performance and accountability report. Retrieved from http://www.va.gov/ budget/report/.

Department of Veterans Affairs (2011). Annual budget submission (FY 2012). Retrieved from http://www.va.gov/budget/products.asp.

Department of Veterans Affairs Form 21-4138. Retrieved from http:// www.vba.va.gov/pubs/forms/vba-21-4138-are.pdf.

Eaton, M. F., Dantiki, S. \& Gugliuzza, P. R. (2010). Ten Federal Circuit cases from 2009 that veterans benefits attorneys should know. American Law Review, 59, 1155-1198.

Forcier v. Nicholson, 19 Vet. App. 414 (2006).

Gambill v. Shinseki, 576 F.3d 1307 (Fed. Cir. 2009).

Gardner v. Shinseki, 22 Vet. App. 415 (2009).

Gilbert v. Derwinski, 1 Vet. App. 49 (1990).

Green v. Derwinski, 1 Vet. App. 121 (1991).

Groves v. Peake, 524 F.3d 1306 (Fed. Cir. 2008).

Guerrieri v. Brown, 4 Vet. App. 467 (1993).
Haas v. Shinseki, 22 Vet. App. 385 (2009).

Harris, D. (2007). Findings from raters and VSOs surveys. Retrieved from https://www.1888932-2946.ws/vetscommission/edocumentmanager/gallery/Documents/2007_July/CNA_ Raters\&NVSO-Survey_FinalReport.pdf.

Helfer, L. R. (1992). The politics of judicial structure: Creating the United States Court of Veterans Appeals. Connecticut Law Review, 25, 162-171.

Holton v. Shinseki, 557 F.3d 1362 (Fed. Cir. 2009).

Institute of Medicine of the National Academies (2007). A 21st century system for evaluating veterans for disability benefits.

Jandreau v. Nicholson, 492 F.3d 1372 (Fed. Cir. 2007).

Jones v. Shinseki, 23 Vet. App. 382 (2010).

Joyce, P. (2006). April 24). Ninth Judicial Conference of the United States Court of Appeals for Veterans Claims (CLII): Transcript.

Kahana v. Shinseki, 24 Vet. App. 428 (2011).

Layno v. Brown, 6 Vet. App. 465 (1994).

Light, P. C. (1992). Forging legislation. New York: Norton.

Mashaw, J. L. (2001). Small things like reasons are put in a jar: Reason and legitimacy in the administrative state. Fordham Law Review, $70,17-35$

Mattern v. West, 12 Vet. App. 222 (1999).

Mauerhan v. Principi, 16 Vet. App. 436 (2002).

Maxson v. Gober, 230 F.3d 1330 (Fed. Cir. 2000).

McLendon v. Nicholson, 20 Vet. App. 79 (2006).

Miller v. West, 11 Vet. App. 345 (1998).

Mittleider v. West, 11 Vet. App. 181 (1998).

Moore v. Nicholson, 21 Vet. App. 211 (2007), rev'd on other grounds sub nom. Moore v. Shinseki, 555 F.3d 1369 (Fed. Cir. 2009).

National Organization of Veterans Advocates v. Department of Veterans Affairs, No. 10-7136 (Fed. Cir. argued Aug. 5, 2011).

Nieves-Rodriguez v. Peake, 22 Vet. App. 295 (2008).

Owens v. Brown, 7 Vet. App. 429 (1995).

Paralyzed Veterans of America et al. (2011). The independent budget for the Department of Veterans Affairs fiscal year 2012. Retrieved from http://www.independentbudget.org/.

Parker, J. (2009). Two perspectives on legal authority within the Department of Veterans Affairs adjudication. Veterans Law Review, 1, 208-221.

Pentecost v. Principi, 16 Vet. App. 124 (2002).

Polovick v. Shinseki, 23 Vet. App. 48 (2009).

Reonal v. Brown, 5 Vet. App. 458 (1993).

Ridgway, J. D. (2009a). Lessons the veterans benefits system must learn on gathering expert witness evidence. Federal Circuit Bar Journal, 18, 405-428.

Ridgway, J. D. (2009b). Why so many remands?: A comparative analysis of appellate review by the United States Court of Appeals for Veterans Claims. Veterans Law Review, 1, 113-166.

Ridgway, J. D. (2010). The Veterans' Judicial Review Act twenty years later: Assessing the new complexities of VA adjudication. New York University Annual Survey of American Law, 66, 251-298.

Riley, R. E. (2010). Simplify, simplify, simplify - An analysis of two decades of judicial review in the veterans' benefits adjudication system. West Virginia Law Review, 113, 67-93.

Robinson v. Peake, 21 Vet. App. 545 (2008), aff'd sub nom. Robinson v. Shinseki, 557 F.3d 1355 (Fed. Cir. 2009).

Roper v. Nicholson, 20 Vet. App. 173 (2006).

Sacks v. West, 11 Vet. App. 314 (1998).

Sanchez-Benitez v. West, 13 Vet. App. 282 (1999), dismissed in part and vacated in part on other grounds, Sanchez-Benitez v. Principi, 259 F.3d 1356 (Fed. Cir. 2001)

Sanders v. Principi, 17 Vet. App. 232 (2003).

Savage v. Shinseki, 24 Vet. App. 259 (2011).

Savage v. Gober, 10 Vet. App. 488 (1997).

Schram, M. (2008). Vets under siege: How America deceives and dishonors those who fight our battles. New York: Thomas Dunne. 
Sellers v. Principi, 372 F.3d 1318 (Fed. Cir. 2004).

Sizemore v. Principi, 18 Vet. App. 264 (2004).

Stefl v. Nicholson, 21 Vet. App. 120 (2007).

Stender, W. W., \& Walker, E. (1974). The National Personnel Records Center fire: A study in disaster. The American Archivist, 37. Retrieved from http://www.archives.gov/st-louis/military-personnel/ nprc-fire.pdf.

Stover v. Mansfield, 21 Vet. App. 485 (2007).

Stressor Determinations for Posttraumatic Stress Disorder, 75 Fed. Reg. 39,843, 39,843 (Jul. 13, 2010).

Suozzi v. Brown, 10 Vet. App. 307 (1997).

Swann v. Brown, 5 Vet. App. 229 (1993).

Terry, J. P. (2011). Report of the Chairman of the BVA for fiscal year 2010. Retrieved from http://www.bva.va.gov/Chairman Annual_Rpts.asp.

Thun v. Peake, 22 Vet. App. 111 (2008), aff'd sub nom. Thun v. Shinseki, 572 F.3d 1366 (Fed. Cir. 2009).

Vasquez-Flores v. Shinseki, 580 F.3d 1270 (Fed. Cir. 2009).

Veterans' Disability Benefits Commission (2007). Honoring the call to duty: Veterans' disability benefits in the 21st century (produced pursuant to Pub. L. No. 108-136).

Veterans' Judicial Review Act, Pub. L. No. 100-687, 102 Stat. 4105 (1988).

Walch v. Shinseki, 563 F.3d 1374 (Fed. Cir. 2009).

White v. Principi, 243 F.3d 1378 (Fed. Cir. 2001).
Zang v. Brown, 8 Vet. App. 246 (1995).

Federal Rule of Evidence 702.

38 C.F.R. $\S 3.110$ (2011).

38 C.F.R. $\S 3.157$ (2011).

38 C.F.R. $\S 3.301$ (2011).

38 C.F.R. $\S 3.302$ (2011).

38 C.F.R. $\S 3.303$ (2011).

38 C.F.R. $\S 3.304$ (2011).

38 C.F.R. $\S 3.309$ (2011).

38 C.F.R. $\$ 3.321$ (2011).

38 C.F.R. $\S 3.354$ (2011).

38 C.F.R. ch. 4 (2011).

38 C.F.R. § 4.2 (2011).

38 C.F.R. $\S 4.7$ (2011).

38 C.F.R. § 4.16 (2011).

38 C.F.R. $\$ 4.130$ (2011).

38 U.S.C. § 101 (2002).

38 U.S.C. § 1101 (2002).

38 U.S.C. $§ 1110$ (2002).

38 U.S.C. \& 1131 (2002).

38 U.S.C. § 1154 (2002).

38 U.S.C. $\S 5103$ (2002).

38 U.S.C. § 5303 (2002).

38 U.S.C. § 7292 (2002). 